\title{
ÁGUA COMO UM BEM SOCIAL PÚBLICO: OS PROCESSOS DE PRIVATIZAÇÃO FACE AO ABASTECIMENTO PÚBLICO EM PAU DOS FERROS-RN
}

\author{
Izidio Rocha da Silva Júnior ${ }^{1}$ \\ Larissa da Silva Ferreira Alves ${ }^{2}$ \\ Jorge Luís de Oliveira Pinto Filho ${ }^{3}$
}

Resumo: A água é um recurso natural considerada um bem social público e de uso comum. Entretanto, atualmente esse bem vem sendo comprometido pelo viés econômico, principalmente pelos de hodiernos processos de privatizações de concessionárias de abastecimento de água no Brasil e no mundo. Desta forma, o presente estudo tem por objetivo debater a importância do caráter público das concessionárias de água como mecanismo de garantir minimamente acessos mais justos à água. Para tanto, buscou-se mostrar exemplo desses acessos, como o papel das tarifas sociais da abastecimento de água especificamente de uma cidade do Semiárido brasileiro denominado Pau dos Ferros, estado do Rio Grande do Norte. Como método de pesquisa, aporta-se na dialética como forma de ver as disparidades sociais historicamente construídas por mecanismos perversos de controle da sociedade e de mecanismos de/para reprodução do capital. Como procedimentos metodológicos fez-se levantamento teórico e documental a respeito da água enquanto um bem público, realizou-se pesquisas sobre a variação tarifária de concessionárias privadas em contraponto às públicas e como isso influencia principalmente o acesso à água a famílias pobres. Empiricamente, estudou-se as tarifas sociais da referida cidade no período de 2017, com base nos dados da Companhia de Abastecimento de Água e Esgoto do Rio Grande do Norte (CAERN). Através dessa tarifa social constatou-se que a companhia diminui os laços das desigualdades e garante para muitas famílias um baixo custo ao acesso a água. Mostra ainda a discrepância do tarifário de concessionárias públicas e privadas. Espera-se com esse artigo ampliar-se a consciência da responsabilização do Estado enquanto provedor dos serviços de abastecimento de água e chamar a sociedade ao debate do direito à água.

Palavras-chave: Água como um bem social; Abastecimento de água; Privatização da água; Recursos Hídricos

\section{WATER AS A PUBLIC SOCIAL WELFARE: THE PRIVATIZATION PROCESSES IN THE FACE OF PUBLIC SUPPLY IN PAU DOS FERROS-RN}

\footnotetext{
Abstract: Water is a natural resource considered a public social good and in common use. However, nowadays this property has been compromised by the economic bias, mainly by the current privatization processes of water supply concessionaires in Brazil and in the world. Thus, the present study aims to discuss the importance of the public character of water

${ }^{1}$ Contador Técnico da Companhia de Abastecimento de Água e Esgoto do Rio Grande do Norte (CAERN) e Especialista em Gestão Pública da Universidade do Estado do Rio Grande do Norte (UERN) - Campus CAMEAM, Pau dos Ferros-RN. E-mail: juninhoizidio@ hotmail.com

${ }^{2}$ Licenciada em Geografia e Profa. Dra. do Curso de Geografia e do Programa de Pós-Graduação em Planejamento e Dinâmicas Territoriais no Semiárido (PLANDITES), da Universidade do Estado do Rio Grande do Norte (UERN) - Campus CAMEAM, Pau dos Ferros-RN. E-mail: larissa0185@ gmail.com

${ }^{3}$ Gestor ambiental e Prof. Dr. do Curso de Engenharia Ambiental e Sanitária da Universidade Federal Rural do Semiárido (UFERSA) e do Programa de Pós-Graduação em Planejamento e Dinâmicas Territoriais no Semiárido (PLANDITES), da Universidade do Estado do Rio Grande do Norte (UERN) - Campus CAMEAM, Pau dos Ferros-RN. E-mail: jorge.filho@ufersa.edu.br
} 
concessionaires as a mechanism to guarantee minimally access to water. To do so, we sought to show an example of such accesses, such as the role of domestic rates for water supply specifically from a Brazilian semi-arid city called Pau dos Ferros, Rio Grande do Norte state. As a research method, it is based on the dialectic as a way of seeing the social disparities historically constructed by perverse mechanisms of society's control and mechanisms of / for reproduction of capital. As methodological procedures, a theoretical and documentary survey was made on water as a public good. Research was carried out on the rate variation of private concessionaires as opposed to public ones, and since this mainly influences access to water for poor families. Empirically, the city's social rates were studied in the period of 2017, based on data from the Water Supply Company of Rio Grande do Norte (CAERN). Through this social rate it was found that the company reduced the links of inequalities and guarantees many families a low cost to access water. It also shows the discrepancy of the rates of public and private concessionaires. This article is expected to expand awareness of the State's responsibility as provider of water supply services and call society to the debate on the right to water.

Keywords: Water as a social good; Water supply; Privatization of water; Water resources

\section{EL AGUA COMO UN BIEN SOCIAL PÚBLICO: LOS PROCEDIMIENTOS DE PRIVATIZACIÓN FRENTE AL ABASTECIMIENTO PÚBLICO EN PAU DOS FERROS-RN}

Resumen: El agua es un recurso natural considerado un bien social público y de uso común. Sin embargo, actualmente ese bien viene siendo comprometido por el factor económico, principalmente por los actuales procesos de privatizaciones de concesionarias de abastecimiento de agua en el Brasil y en el mundo. De esta forma, el presente estudio tiene por objetivo debatir la importancia del carácter público de las concesionarias de agua como mecanismo de garantizar mínimamente accesos más equitativos al agua. Para ello, se buscó mostrar esos accesos, como por ejemplo, el papel de las tarifas sociales del abastecimiento de agua, específicamente, de una ciudad del Semiárido brasileño denominada Pau dos Ferros, estado del Rio Grande do Norte. El método de investigación se fundamenta en la dialéctica como forma de ver las desigualdades sociales históricamente construidas por mecanismos inicuos de control de la sociedad y de mecanismos de/para reproducción del capital. Como procedimientos metodológicos se realizó un levantamiento teórico y documental con respecto al agua como un bien público, se realizaron investigaciones sobre la variación tributaria de concesionarias privadas en contrapunto a las públicas y cómo eso influye, principalmente, el acceso al agua a las familias pobres. Empíricamente, se estudiaron las tarifas sociales de la referida ciudad, en el período de 2017, según los datos de la Compañía de Abastecimiento de Agua y de Alcantarillado del Rio Grande do Norte - Companhia de Abastecimento de Água e Es goto do Rio Grande do Norte (CAERN). A través de esa tarifa social se constató que la compañía disminuye los lazos de las desigualdades y garantiza para muchas familias un bajo costo al acceso del agua. También muestra la discrepancia de la tarifa de concesionarias públicas y privadas. Con este estudio se espera ampliar la conciencia de la responsabilidad del Estado como proveedor de los servicios de abastecimiento de agua y llamar a la sociedad al debate del derecho al agua.

Palabras clave: El agua como un bien social; Abastecimiento de agua; Privatización del agua; Recursos hídricos 


\section{INTRODUÇÃO}

A água é essencial à vida e todos os organismos vivos no planeta Terra dela dependem para a sua sobrevivência (TUNDISI, 2003). É apontada como um recurso renovável e inesgotável na natureza (TUCCI, 2008), porém é fator de preocupação sua disponibilidade e qualidade, necessitando de uma atenção prioritária do poder público e da sociedade, para que seja possível promover a utilização sustentável desse recurso (NEUTZLING, 2004).

Nesse sentido, observa-se que a água pode ser utilizada para diversos fins: consumo humano; atividades agrícolas e pecuárias; geração de energia; transporte; abastecimento industrial; pesca e aquicultura e turismo e lazer (DERÍSIO, 2012). Ainda é possível acrescentar os usos múltiplos da água para: preservação da flora e fauna; harmonia paisagística e diluição de efluentes (VON SPERLING, 2005).

Diante destes usos conflitantes, diversas alterações das características desses recursos hídricos resultam em processos de poluição hídrica de naturezas variadas (VON SPERLING, 2005), a saber: poluição térmica (decorrente da descarga de efluentes a altas temperaturas); poluição química (consiste na introdução de substâncias tóxicas na água) e; poluição biológica (resultante da descarga de bactérias patogênicas, vírus e outros organismos) (BENN; MCAULIFFE, 1981).

Esses processos de poluição resultam em efeitos adversos e maléficos relacionados com as dimensões: ambiental, sanitária, social, econômica, saúde, territorial e política (CARVALHO \& OLIVEIRA, 2003; MARTINELLI, 2009; DERÍSIO, 2012).

Desta forma, surgem as políticas ambientais com ênfase nos recursos hídricos com a finalidade de proteger as águas dentro do sistema nacional de meio ambiente, a partir de uma gestão preocupada em integrar esses recursos ao meio. Para garantir o desenvolvimento sustentável e à manutenção do meio ambiente ecologicamente equilibrado, no caso do Brasil surgiram instrumentos como o Código das Águas de 1934, Constituição de 1988, Lei n ${ }^{\circ}$ 9.433/1997 das Águas, que instituiu a Política Nacional de Recursos Hídricos (PNRH) e o Sistema Nacional de Gerenciamento de Recursos Hídricos (SINGREH).

Concomitantemente, ao longo do tempo a temática dos recursos hídricos vem sendo pesquisada por diversas abordagens: definição e conceituação (BRAGA, 2012); usos dos recursos hídricos (DERÍRISO, 2012); poluição hídrica (SPIRO E STIGLIANI, 2009); consequências da poluição (MARTINELLI, 2009); recursos hídricos e saúde (CARVALHO \& OLIVEIRA, 2003); técnicas de controle da poluição hídrica (VON SPERLING, 2005), 
atuação do poder público e recursos hídricos (NEUTZLING, 2004); perspectivas futuras dos recursos hídricos (TUCCI, 2008; TUNDISI, 2003) etc. Entretanto, existe uma lacuna de estudos que tratam da análise institucional do uso dos recursos hídricos, sob uma sob uma perspectiva da privatização e direito à água no Brasil.

Desta maneira, tornam-se fundamentais investigações relacionadas com o debate em torno da privatização e do direito à água, principalmente em nível de Brasil tendo em vista um novo contingente de privatizações a se estabelecer no país.

A problemática dos recursos hídricos não está restrita apenas aos grandes centros urbanos. No Semiárido brasileiro, essa discussão precisa ser maior enfatizada, principalmente devido as limitações hidrológicas e climáticas dessa região. Nesse contexto, apresenta-se a região do Alto Oeste do Estado do Rio Grande do Norte, onde localiza-se a cidade de Pau dos Ferros que apresenta uma população de 27.745 habitantes conforme o censo do Instituto Brasileiro de Geografia e Estatística (IBGE) realizado no ano de 2010, com uma estimativa de aumento para 30.206 habitantes no ano de 2017. A centralidade da cidade em ofertas de serviços na região favorece o deslocamento de pessoas diariamente, tanto de cidades vizinhas do RN quanto de outras localidades dos estados circunvizinhos, Paraíba e Ceará, tendo como um dos resultados dessas dinâmicas populacionais a pressão no sistema de abastecimento de água potável na cidade, além da forte conjuntura de seca, que vem impondo o debate do acesso à água no seio das questões sociais na perspectiva do direito ao acesso a esse recurso natural.

Com base nessa situação, este estudo partiu de algumas questões: quem tem direito ao acesso à água? Como os mais pobres são mais prejudicados pela perspectiva da água como um bem econômico, e não social? Qual a importância do caráter público das concessionárias de água como mecanismo de garantir minimamente acessos mais justos à água? Como a perspectiva social é interpretada pela companhia de abastecimento de água em Pau dos Ferros-RN?

Nesse enredo, o presente estudo buscou investigar a importância do caráter público das concessionárias de água como mecanismo de garantir minimamente acessos mais justos à água. Para tanto, buscou-se mostrar o exemplo das tarifas sociais da abastecimento de água em Pau dos Ferros-RN. Como objetivos específicos têm-se: compreender a água como um bem social público; descrever o papel das concessionárias no abastecimento de água no Brasil; contextualizar a realidade de privatização da água no Brasil e no mundo; apontar os benefícios da concessionária pública de abastecimento de água do Rio Grande do Norte; além de mapear a tarifa social na cidade de Pau dos Ferros-RN. 
Além dessa INTRODUÇÃO, o trabalho está dividido nas seguintes seções: REFERENCIAL TEÓRICO com os tópicos: ÁGUA: UM BEM SOCIAL PÚBLICO, que aborda as características gerais e sociais desse bem; CONCESSIONÁRIAS DE ABASTECIMENTO DE ÁGUA, que faz um relato sobre o atual estágio de abastecimento de água por via de concessionárias e; PRIVATIZAÇÃO DA ÁGUA NO MUNDO, AMÉRICA DO SUL E BRASIL, que discute como é importante a sociedade se atentar ao tema. MATERIAIS E MÉTODOS, que aborda e delimita a área de estudo, define a classificação da pesquisa e, traça os procedimentos metodológicos. RESULTADOS E DISCUSSÃO, que relata sobre a ÁGUA E OS BENEFÍCIOS DAS CONCESSIONÁRIAS PÚBLICAS: O EXEMPLO DO ESTADO DO RIO GRANDE DO NORTE, mostrando a importância da CAERN para o estado do RN e para Pau dos Ferros-RN, principalmente para famílias pobres beneficiárias de tarifas sociais; CONSIDERAÇÕES FINAIS, que fez apontamentos futuros da temática e; REFER̂̂ECIAS.

\section{REFERENCIAL TEÓRICO}

ÁGUA: UM BEM SOCIAL PÚBLICO

A água é o líquido mais importante do nosso planeta, sendo essencial à vida e todos os organismos vivos na Terra dependem da água para sua sobrevivência (TUNDISI, 2003). Sendo apontada como um recurso renovável e inesgotável na natureza (TUCCI, 2008).

Desta forma, apresentada como um elemento natural renovável, diferente de outros elementos, a água faz sua permanência na natureza através de seu ciclo hidrológico, que consiste no continuo movimento da água em nosso planeta. Para Tucci (2008) este processo representa o comportamento da água no globo terrestre, incluindo ocorrência, transformação, movimentação e relações com a vida humana, sendo considerado um verdadeiro retrato dos vários caminhos da água em interação com os demais recursos naturais. A água existe em forma de vapor, na atmosfera, e é proveniente da evaporação de todas as superfícies líquidas (oceanos, mares, rios, lagos, lagoas) ou das superfícies umedecidas com água, como a superfície dos solos. Parte da água que se encontra na atmosfera resulta de fenômenos hidrológicos e também de fenômenos vitais, como a respiração e transpiração

Apesar da possibilidade de renovação, a água doce é um recurso natural bastante escasso e distribuído de forma desigual no planeta. Sua disponibilidade para o consumo humano provém da possibilidade de captação em lagos, rios e aquíferos de menor profundidade. No Brasil, os recursos hídricos superficiais disponíveis em abundância 
representam $11 \%$ do total mundial. No entanto, no país ocorre uma distribuição desigual da água, sendo que somente a bacia hidrográfica do rio Amazonas detém 71,1\% da vazão nacional (TUCCI et al., 2001).

A situação torna-se mais alarmante devido os conflitos dos usos múltiplos da água, que são: consumo humano; atividades agrícolas e pecuárias; geração de energia; transporte; abastecimento industrial; pesca e aquicultura; turismo e lazer; preservação da flora e fauna; harmonia paisagística e; diluição de efluentes (DERÍSIO, 2012; VON SPERLING, 2005). Acrescenta ainda que a água no século XX passou a ser um recurso escasso, passível de gerar conflito de interesses não só entre seres humanos, cidadãos de um mesmo país, mas também entre Estados e nacionalidades, realidade que impunha a necessidade de se estabelecer regras para a utilização da água, visto que quaisquer comunidades, países ou culturas dependeriam de sua disponibilidade, condição básica para a existência de vida no planeta (GRANZIERA, 2001).

Nesta perspectiva, entendemos a água como a base para a maioria das nossas atividades. Porém, o crescimento elevado de seu consumo nas últimas décadas devido ao crescimento populacional, sistemas irrigatórios e grandes indústrias, além da irregular distribuição devido as diferentes regiões climáticas e seus territórios, proporcionou conflitos entre pessoas pela sua manipulação.

Dessa forma, existe o fator de preocupação em relação a quantidade e qualidade da água, já que afetará consequentemente a sua disponibilidade, necessitando assim de uma atenção prioritária do poder público e da sociedade, para que seja possível promover a utilização sustentável desse recurso (NEUTZLING, 2004). Assim, a literatura internacional sobre preservação da água tem incentivado a busca por alternativas para o seu uso, legal e sustentável.

A fim de expandir o reconhecimento da água como um bem social público, o Conselho dos Direitos Humanos da Organização das Nações Unidas (ONU), na cidade de Genebra em 2010, fez um grande pronunciamento em relação da água ser um direito humano.

Segundo o documento produto do momento, entende-se que:

O direito à água e ao saneamento é um direito humano, igual a todos os outros direitos humanos, o que implica que é justiciável e executável", disse a Sra. De Albuquerque. "Daí, a partir de hoje, temos uma responsabilidade ainda maior de concentrar todos os nossos esforços na implementação e na plena realização deste direito essencial. (ONU, 2010, Tradução nossa) 
Com isso, o conselho através de documentos internacionais, especificamente da Resolução da ONU nº 64.292, de 28 de julho de 2010, fala sobre o reconhecimento desse direito humano que é o acesso a água potável e das legais formas de aplicações para combater sua falta diante das pessoas que estão sem um correto fornecimento.

Essa resolução prevê a efetivação de medidas partindo do propósito de que a água e o saneamento são direitos humanos essenciais para a vida de todos. Conclui-se então a partir do entendimento da Organização das Nações Unidas, que o acesso à água é considerado um direito, consequentemente, reconhece-o como direito fundamental-social a ser disponibilizado para todos os indivíduos, ricos e pobres, tendo os órgãos concessionários a capacidade dessa gestão.

Entretanto a partir dos conflitos gerados em torno do uso da água no Brasil, observase que a água vem sendo compreendida de forma diferente, gerando assim questionamentos importantes sobre a água ser ou não um bem público e o poder legal que existe a garantir isso. Seguindo essa linha de raciocínio, para conceituar a água como um bem social público, devemos considerar as palavras de alguns autores que trazem diversas ideias que podem firmar um melhor pensamento a respeito do uso da água como um direito e suas garantias por leis.

Com um conjunto de princípios e normas jurídicas que podem regrar o domínio e uso desse elemento, buscamos as leis que colocam em pauta esses princípios. Inicialmente fazemos vistas em nossa legislação, que de tamanha importância quanto qualquer dever e direito descrito, o acesso à água vem a ser um direito fundamental-social tal como o direito à educação, saúde, alimentação, trabalho e moradia (BRASIL, 1988, Art.6).

O primeiro marco regulatório referente ao domínio e utilização da água no território brasileiro veio através do Decreto $N^{\circ} 24.643 / 1934$, conhecido como o Código de Águas. O referido código assegurou o uso gratuito de correntes e nascentes de águas, com dever de suprir necessidades básicas de vida, permitindo o uso de qualquer reservatório natural público. Na agricultura e indústria tinham um fornecimento relacionado aos instrumentos de concessão jurídica. Os demais casos ocasionados eram preferencialmente concedidos para abastecimento da população.

A água como um dos pilares do meio ambiente deve ser considerada um bem comum de uso, devendo ser coletivamente e moderadamente explorada de forma que atenda às necessidades básicas, fazendo um tipo de administração participativa da população pela água.

Essa administração participativa do povo pela água também é uma forma de proliferar a vida, onde se garante muito mais do que só nossa sobrevivência, uma vida com 
qualidade e dignidade, mas também que garanta toda a biodiversidade existente no planeta. Com isso cada um tem o dever de economizar e cuidar, assim como a gestão dos recursos hídricos tem um foco em administrar um fornecimento ideal, disponibilizado de maneira justa e regrada para que não haja desperdícios.

Pompeu (2010, p. 43) nos traz o entendimento sobre direito de águas afirmando que:

O direito de águas pode ser conceituado como conjunto de princípios e normas jurídicas que disciplinam o domínio, uso, aproveitamento, a conservação e preservação das águas, assim como a defesa contra suas danosas consequências, de início, denominava-se direito hidráulico. A estreita vinculação das normas jurídicas relativas às águas com o ciclo hidrológico, que desconhece limites no seu percurso, faz com que o direito de águas contenha normas tradicionalmente colocadas no campo do direito privado e no do direito público. Suas fontes são a legislação, a doutrina, a jurisprudência e o costume.

Para se manter em obediência com a Constituição, que em seu inciso XIX do Art. 21 estabelece como "competência de a União instituir o sistema nacional de gerenciamento de recursos hídricos", no dia 08 de janeiro de 1997 foi criada a Lei no 9.433 conhecida como a “Lei das Águas", lei na qual vem para instituir a Política Nacional de Recursos Hídrico e criar o Sistema Nacional de Gerenciamento de Recursos Hídricos. Nela podemos encontrar os princípios fundamentais da Política Nacional, que fortalece a compreensão de que a água é um bem público (não podendo ser controlada por particulares) e um recurso natural dotado de valor econômico, que deve ter como prioridade o consumo humano e de animais, em uma gestão descentralizada, com a participação dos usuários, da sociedade civil e do governo. Também está descrito nessa Lei os objetivos que buscam assegurar a disponibilidade de água com qualidade às atuais e futuras gerações, promovendo uma utilização racional e prevenindo contra eventos hidrológicos, sejam naturais ou causados pelo homem.

A Lei das Águas (Lei $n^{\circ} 9.433,1997$ ) veio num momento em que a água já permutava com situações de escassez em seu abastecimento e com a preocupação em sua exploração desordenada. Com isso aponta em seu Art. $5^{\circ}$ a cobrança pelo uso de recursos hídricos. E no Art. $19^{\circ}$ os objetivos específicos para tal cobrança, que pretende reconhecer a água como um bem também econômico e dar ao usuário uma indicação de seu real valor, incentivando a racionalização do uso da água e a obtenção de recursos financeiros para o financiamento dos programas e intervenções contemplados nos planos de recursos hídricos.

Muitos tratam a água apenas como um bem econômico, isso se observadas muitas declarações de políticos e gestores, que utilizam desse bem como instrumento de lucro, o que tem gerado grande problemática acerca de colocar valores reversos ao respeito a água, 
promovendo-a para um bem comercializável, tirando a percepção das pessoas de que a água é um bem comum.

Reafirmando a água como um patrimônio público, o seu valor é de reconhecimento de todos porque a valorização vem da existência de necessidade pela água, e para muitos tem caráter econômico quando se torna de difícil acesso. Como para Granziera (2003, p.56) que, mesmo tendo um entendimento da água como um bem público, afirma sobre a mesma ter um reconhecimento econômico, e esclarece que antes, o não reconhecimento desse valor levou a um alto patamar de desperdício e a danos ambientais decorrentes do uso excessivo. A gestão da água, como bem econômico, além de utilizá-la para custear serviços de coleta, tratamento e distribuição, é uma importante forma de atingir a estabilidade de seu uso e de promover a conservação e proteção.

Com as palavras de Armando; Valadão (2013 p.39), notamos que seus pensamentos definem a água como um bem comum essencial à manutenção da vida no planeta, e pela compreensão de sua natureza jurídica, é um bem ambiental fundamental à garantia da dignidade da pessoa humana. É, pois, um bem comum não sujeito à apropriação privada, na qual faz a necessidade de existir diversos movimentos sociais que lutam contra sistemas neoliberalistas que condicionam processos de apropriação privada. Veremos que essas lutas intensas levantaram diversos questionamentos sobre um bem público de importância incalculável ser usado como gerador de lucros através de sua abusiva mercantilização.

\section{CONCESSIONÁRIAS DE ABASTECIMENTO DE ÁGUA}

Falar em fornecimento de água requer pensar em Saneamento Ambiental. A Lei ${ }^{\circ}$ 11.445, 2007 em seu art.3 $\mathbf{~}^{\mathbf{0}}$, inciso I, descreve o abastecimento de água como um dos quatro pilares básicos do Saneamento, destacando-o como “o conjunto de serviços, infraestruturas e instalações operacionais de: a) Abastecimento de água potável; b) esgotamento sanitário; c) limpeza urbana e manejo de resíduos sólidos; d) drenagem e manejo de águas pluviais”, que são de acesso universal.

Desta forma, a efetivação do saneamento ambiental assegura que a população tenha salubridade ambiental, já que proporciona prevenir a ocorrência de doenças ocasionadas pelo meio ambiente e promover o melhoramento da saúde pública e ecossistema. Dentre os componentes de saneamento ambiental, cabe destacar o abastecimento de água por se tratar a forma mais adequada reduz problemas de doenças por veiculação hídrica.

Nesta perspectiva, o abastecimento de água pode ser concebido e projetado para atender a pequenos povoados ou a grandes cidades, variando nas características e no porte de 
suas instalações, sendo definido pelo conjunto de obras, instalações e serviços, destinados a produzir e distribuir água a uma comunidade, em quantidade e qualidade compatíveis com as necessidades da população, para fins de consumo doméstico, serviços públicos, consumo industrial e outros usos (FUNASA, 2012).

A execução do abastecimento de água tal como os demais que compõem o saneamento básico competem a União, Estados e a esfera municipal, podendo ser repassados para concessionárias públicas ou privadas por meio de contratos de concessão. Através desses contratos, caberá a concessionara satisfazer todos os critérios legais referentes ao serviço de abastecimento de águas, para garantir um fornecimento que supra as necessidades humanas, direitos sociais e claro, preservando o meio ambiente.

As concessionárias estaduais de abastecimento de água e esgotamento sanitário foram criadas em meados de 1960 e, em alguns anos, se firmaram como principais ofertadores dessa prestação de serviços em águas e esgotos no Brasil, pois contavam com grandes investimentos por parte do governo e captação financeira por meio de operações de crédito junto a instituições bancárias (OLIVEIRA; LIMA, 2015). Na década de 1980, a concretização destas empresas começou a entrar em crise com a extinção do Banco Nacional de Habitação, órgão de grande importância como financiador. O país passou por momentos de turbulência econômica e as fontes de recursos estavam se esgotando, igualmente no tempo que terminava o período de carência dos empréstimos e aumentavam as despesas com encargos da dívida. (TUROLLA, 2002).

Continuando no pensamento de Turolla (2002, p. 09), o início dos movimentos favoráveis à privatização viera seguidamente "com a definição de um cronograma de transformação das autoridades de bacia em companhias públicas limitadas”, constituindo-se na abertura de capital das estatais e na venda de ações.

Porém, Cavalcanti (2014, p. 95) apresenta dúvidas com relação ao serviço de água sendo oferecido por uma companhia privada ou pública. Segundo o autor, ter o serviço de distribuição de água privatizado ou ter esse serviço provido pelo próprio Estado não é, respectivamente, uma garantia de que o mesmo será satisfatório, nem de que ele será ruim, é necessário verificar caso a caso para assim poder tirar algumas conclusões.

A questão é que o processos de desestatização da água traz à tona diversos fatores, como a sua utilização em prioridade para o comércio, setor produtivo, que é o caso da agroindústria, inclusive na produção de energia, deixando em segundo plano o uso que seria de maior sensibilidade, a população propriamente dita. (CAVALCANTI, 2014, p. 93) Esse autor expressa um questionamento significativo: "qual seria o foco do gerenciamento da 
água? Uma gestão pública (pelos governos e populações) ou uma gestão privada (pelas empresas transnacionais)?"

Com isso Moreira; Pereira (2016, p. 216) compartilham uma ideia semelhante e contemplam que a privatização limita o acesso livre à água, que tem seu principal uso pessoal para cozinhar, beber e higiene, tendo em vista que a transformam em mercadoria, ficando em um patamar de privado, com valor mormente econômico. Como consequência, os autores afirma que "em alguns casos em que ocorreram a privatização da água a população mais carente teve o acesso de forma deficiente ou ficou sem disponibilidade face aos altos preços, colocando em risco a vida desta parte da população". (MOREIRA; PEREIRA, 2016, p.217)

Uma visão direcionada para a água como mercadoria acaba dificultando o acesso à população mais carente, e isso é a privatização. Apresentada como uma das preocupações por Shiva, tratada no documentário "Por Um Fio" (2013), que afirma que a privatização "vai aprofundar a crise para os pobres, porque a água é um produto e o pobre não tem poder aquisitivo para comprá-la. [...] Você está dizendo ao pobre que o mesmo não tem direito à vida, pois sem água, não há vida." Com isso, é importante avaliar em termo de consequência, que uma população com difícil acesso à água por condições precárias virá a sofrer cada vez mais em decorrência da privatização e da supervalorização enquanto produto. (SHIVA apud MOREIRA; PEREIRA 2016, p. 219).

Para tanto, observa-se que a privatização do abastecimento de água é conflitante com a legislação brasileira sobre recursos hídricos, já que a PNRH prever que a água é um bem de domínio público (Inciso I); a água é um recurso natural limitado, dotado de valor econômico (Inciso II); em situações de escassez, o uso prioritário dos recursos hídricos é o consumo humano e a dessedentação de animais (Inciso III); a gestão dos recursos hídricos deve sempre proporcionar o uso múltiplo das águas (Inciso IV); a bacia hidrográfica é a unidade territorial para implementação da Política Nacional de Recursos Hídricos e atuação do Sistema Nacional de Gerenciamento de Recursos Hídricos (Inciso V); a gestão dos recursos hídricos deve ser descentralizada e contar com a participação do Poder Público, dos usuários e das comunidades (Inciso VI). Nisso, insurge a necessidade do debate sobre a privatização da água, principalmente se colocarmos à tona a ótica de todos os direitos e legislações que a garante imediatamente para as populações.

\section{PRIVATIZAÇÃO DA ÁGUA NO MUNDO, NA AMÉRICA E NO BRASIL}

A privatização da água no mundo tem uma longa história. Através de estudos realizados sobre a privatização, a fim de saber a real situação desse processo para a 
população, nos últimos 15 anos foram encontrados ao menos 180 casos de reestatização do fornecimento de água e esgoto em 35 países.

Segundo a ONU (2016), cidades como Paris (França), Berlim (Alemanha), Buenos Aires (Argentina), Budapeste (Hungria), La Paz (Bolívia) e Maputo (Moçambique) são exemplos de localidades que tiveram os seus serviços de fornecimento de água de volta para as mãos da administração pública, ocorrendo uma totalidade de 136 casos em países de alta renda e 44 casos em países de baixa e média renda.

O relator Heller (ONU, 2016), em suas palavras sobre Nações Unidas Para as Águas, declarou que as empresas privadas não realizam investimentos que supram as necessidades de todos e adotam uma política de exclusão fazendo uma divisão na população onde os pobres serão esquecidos, já que impõem tarifas altas, visam grandes arrecadações, além de lhes faltarem ao alcance de metas e obrigações contratuais. E ressalta que o próprio Banco Mundial, que antes defendia as privatizações no saneamento, já reconhece que a iniciativa privada não é uma cura para os problemas. Então passou a existir quebras de contratos e não renovações pois as metas de universalização não eram alcançadas, além dos problemas e dificuldades no monitoramento dos serviços por parte do setor público. Logo, sem transparência não tem como monitorar.

Seguindo um padrão na comunidade europeia, a privatização teve um crescimento considerável com uso de estratégia política, porém trouxe uma eventual elevação de impostos com a intenção de fazer frente aos investimentos, como cita Turolla:

\footnotetext{
"Ainda que particularmente associada ao programa conservador, a privatização pode ter sido impulsionada pelos elevados padrões de qualidade de água e de esgoto introduzidos pela Comunidade Europeia. Dado que o investimento vinha sofrendo cortes nos trinta anos precedentes, a conformidade com esses padrões poderia envolver somas de recursos suficientemente elevadas para criar um ônus eleitoral em uma eventual opção de elevação de impostos para fazer frente aos investimentos" (TUROLLA, 2002 P. 9).
}

Quando se aumenta os impostos de forma tendenciosa, a fim de cobrir cortes e gastos, as classes sociais tendem a sofrer primeiramente. Com isso, o Conselho Mundial das Águas, entra em conflito com empresas prestadoras do serviço de saneamento que pretendiam transformar a água em recursos econômicos. São: "As empresas britânicas Severn Trent, Anglian Water e Kelda Group, as espanholas OHL e Águas de Barcelona (Agbar), as francesas Suez, Bouygues-SAUER e Vivendi, a alemã RWE-Thames Water, as norteamericanas The Capital Group Companies, Bechtel-United Utilities e American Works Company." (CAVALCANTI, 2014 p.92) 
Em muitos países existiram conflitos entre a população e o governo a fim de uma forma que sanasse a necessidade de um fornecimento de água adequado e por um preço justo para todas as classes. Na Bolívia existiu o que chamamos de "Guerra das Águas", em que movimentos em contraponto aos malefícios impostos pela companhia privada, colocaram milhões de pessoas nas ruas em luta contra a privatização, unificando forças de uma forma que conseguiram tomar de volta o que de fato é do povo. Vemos isso na citação de Sader:

\begin{abstract}
"Podemos dizer que primeira batalha pela água se deu por aqui, na Bolívia, quando o Banco Mundial exigiu, para a renovação de um empréstimo de 25 milhões de dólares, a condição de que fossem privatizados os serviços de água do país mais pobre da América do Sul. Quando foi privatizado o serviço hídrico da cidade de Cochabamba à poderosa empresa estadunidense Bechtel, o preço da água aumentou brutalmente já nos dois primeiros meses. Como resposta, dezenas de milhares de pessoas tomaram as ruas de Cochabamba para manifestar seu protesto pelo aumento dos preços e os cortes feitos pela empresa com os devedores. O movimento desembocou em uma greve geral que paralisou a cidade, o que obrigou a Bechtel a fazer as malas e fugir da Bolívia, embora não por muito tempo. Regressou com uma demanda de 25 milhões de dólares contra o governo boliviano, exigindo o pagamento de indenizações por perda de lucros. Outras zonas do continente são cenário de lutas similares, entre elas a Argentina, o Uruguai - em que o povo decidiu em plebiscito simultâneo às eleições presidenciais impedir qualquer forma de privatização dos serviços de água -, o Chile, a Guatemala, o México, que vivem movimentos similares na América Latina.” (SADER, 2005, p. 1)
\end{abstract}

Destacando alguns países onde apresentou um grande índice de cidades com o serviço de fornecimento de água privatizado, estão o Uruguai, a Argentina e a Bolívia. Algumas regiões passaram um período maior, outras em rápido intervalo de tempo, as empresas se mantiveram nesses países até meados de 2006. A reestatização ocorreu pelos mais variados motivos, entre eles a rescisão por parte das empresas privada, por falência e, em sua maioria, por decreto. Vejamos um quadro a seguir com exemplo de algumas das principais cidades da América do Sul:

Quadro 01: Exemplo de cidades que passaram por privatização na América do Sul

\begin{tabular}{|l|l|l|}
\hline \multicolumn{1}{|c|}{ Local } & \multicolumn{1}{c|}{ Privatização } & \multicolumn{1}{c|}{ Reestatização } \\
\hline Buenos Aires & $1993-$ Suez & 2006 - Decreto \\
\hline Santa Fe & $1995-$ Suez & 2005 - Rescisão por parte da Suez \\
\hline Tucumán & $1995-$ Vivendi & 1998 - Rescisão por parte da Vivendi \\
\hline Cordoba & $1997-$ Suez & Não informado \\
\hline La Paz e El Alto & $1997-$ Suez & 2005 - Decreto \\
\hline Maldonado & $1998-$ Suez & $2005-$ Decreto \\
\hline Cochabamba & $1999-$ Bechtel & 2000 - Decreto \\
\hline Buenos Aires & $1999-$ Enron & 2002 - Falência da Enron \\
\hline Maldonado & 2000 - Aguas de Bilbao & 2005 - Decreto \\
\hline Buenos Aires & 2000 - Impregilo & 2006 - Decreto \\
\hline
\end{tabular}

FONTE: FLORES, R. K. (2009, P. 59) 
No Brasil está havendo uma recente defesa à privatização das estatais de abastecimento de água, principalmente por parte dos governos estaduais. Pressionados e amarrados por influência externa no oferecimento de contratos para novos financiamentos e de refinanciamento de dívidas, muitos governos estão aceitando a privatização dos seus serviços à empresas privadas, inclusive os mais básicos deles que um ser humano possa depender: o abastecimento de água pelo saneamento.

O Banco Nacional de Desenvolvimento Econômico e Social (BNDES) em 2016 começou uma série de contratos de estudos com a finalidade de apresentar quais empresas prestadoras do serviço de saneamento entrariam no rol da privatização. Com isso muitos estados estavam no primeiro grupo. Sequencialmente, em fevereiro de 2017 o BNDS divulgou o início do processo de contratação de estudos para outro grupo de estados, que inclui alguns do Nordeste, como Ceará, Paraíba e Rio Grande do Norte. Além deles também estão o Acre e Santa Catarina. Esses estudos indicaram, ainda, qual seria o modelo de desestatização mais indicado para cada estado.

No Estado do Rio de Janeiro, o processo de venda da Companhia Estadual de Águas e Esgotos do Rio de Janeiro (CEDAE) está gerando conflitos entre a classe política, que força uma privatização, e o povo, que necessita da companhia em sua permanência pública. Essa privatização, já aprovada em plenário, vai de encontro ao processo de reestatização das empresas de saneamento básico no Brasil e no mundo, e deixa dúvidas sobre seu real motivo (ONU, 2016). Percebe-se em um discurso afirmativo que a privatização do sistema seria uma saída para resolver problemas existentes. Contudo, o próprio relator da ONU, Leo Heller em 2016 atenta que "não é essa a lição de experiências de privatização em outras partes do mundo. Por trás desse discurso poderíamos ler uma tentativa de afastamento do Estado em sua obrigação de oferecer saneamento" (ONU, 2016). Assim, o órgão público foge de suas obrigações e responsabilidades abrindo portas para consequências relevantes que podem ocorrer na venda do patrimônio público, deixando-o nas mãos da iniciativa privada.

A ONU também atenta em referência a grande quantidade de pessoas que existem no Brasil sem acesso a água em condições adequadas, que é uma necessidade imensa de mais investimentos públicos continuados, que estejam em avanços contínuos, diferentemente da privatização, que vem se mostrando de forma inadequada no mundo afora.

O Brasil tem $40 \%$ de sua população sem acesso adequado à água e $60 \%$ sem acesso a esgotamento sanitário. Apesar da evolução nas últimas décadas, o quadro 
permanece preocupante e, para solucioná-lo, são necessários mais investimentos públicos continuados, enquanto a privatização desses serviços já se mostrou inadequada em diversos países. (ONU, 2016)

$\mathrm{Na}$ medida em que se entrega esse serviço ao capital privado, o poder e o retorno financeiro serão visados como lucro, não permitindo assim que o estado crie ferramentas para proteger o povo da reprodução do capital. Desse modo, entrega uma empresa construída com o dinheiro público, patrimônio construído com dinheiro do povo através de seus impostos pagos ao Estado, com dever de retornar em forma de investimento, porém, nessa lógica passará a ser o lucro do mercado privado.

\section{MATERIAIS E MÉTODOS}

\section{ÁREA DE ESTUDO}

A cidade de Pau dos Ferros/RN é o polo da região interiorana e centro de apoio a 37 municípios do entorno imediato, possui cerca de 30 mil habitantes e mais de 11 mil famílias compondo o fornecimento de água potável. Cidade a qual passa por forte crise hídrica, assim como uma grande maioria das cidades que contemplam a região do semiárida. Território com ênfase na luta por racionalização e valorização da água como um bem vital.

Figura 01: Localização do município de Pau dos Ferros no contexto do estado do Rio Grande do Norte (RN)

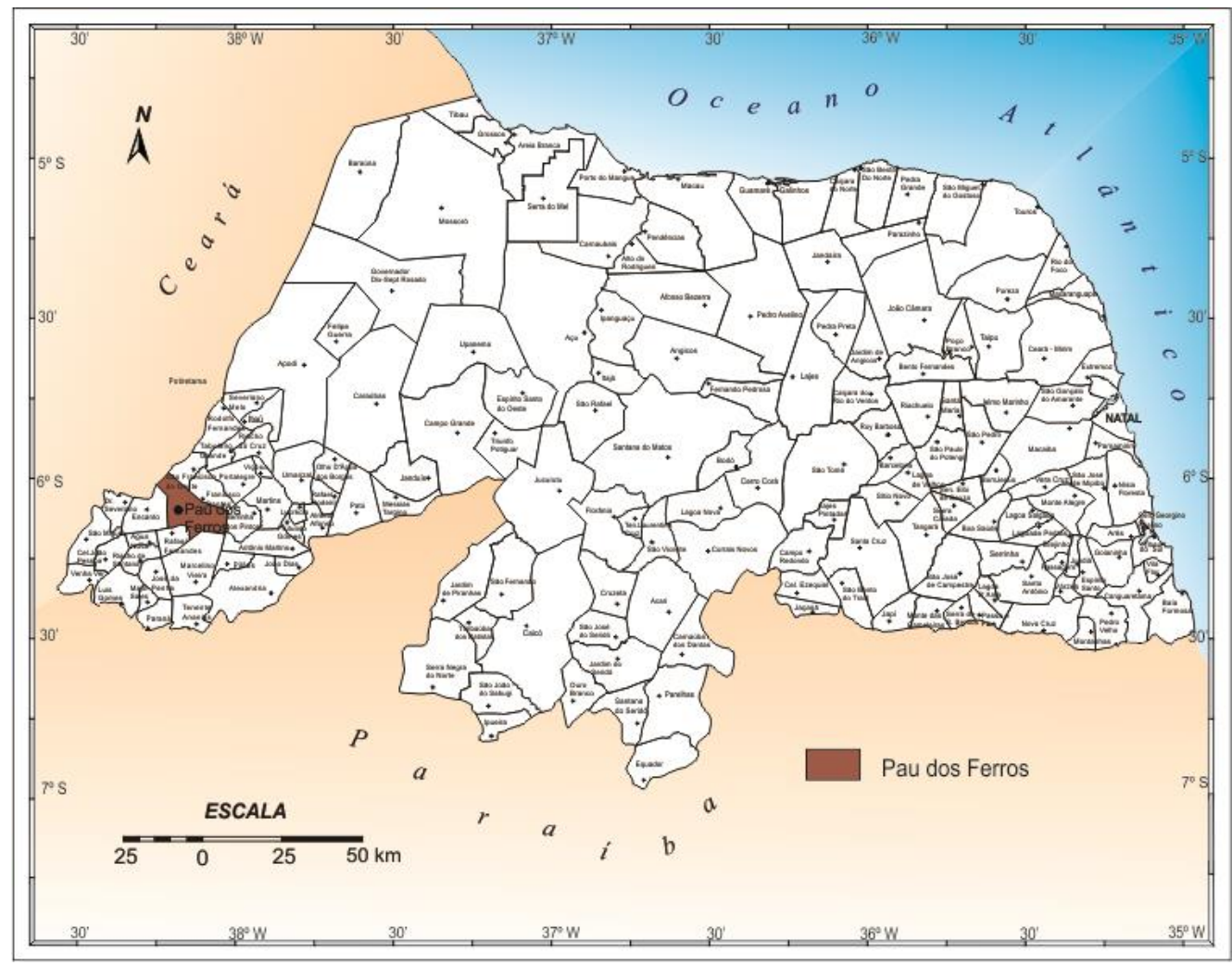


Fonte: Mapa base do IBGE, 2005, adaptado pelos autores, 2017.

\section{CLASSIFICAÇÃO DA PESQUISA}

A pesquisa classifica-se conforme sua finalidade em descritiva (registra e descreve as características do abastecimento público de água em Pau dos Ferros-RN) e, exploratória (torna a problemática do abastecimento mais explícita a partir da exploração da tarifa social). Do ponto de vista dos procedimentos técnicos, enquadra-se como pesquisa de campo (envolve a coleta de dados da população contemplada na tarifa social através de pesquisa documental), bibliográfica (levantamento bibliográfico sobre água como bem social, privatizações de abastecimento de água e, concessionárias privadas (PRODANOV; DE FREITAS, 2013). Parte da perspectiva da dialética, tendo em vista que a leitura aqui posta visa o entendimento e interpretação das disparidades sociais historicamente construídas por mecanismos perversos de controle da sociedade e de meios de/para reprodução do capital, no caso às vinculadas ao controle da água e sua distribuição desigual.

\section{PROCEDIMENTOS METODOLÓGICOS}

O presente trabalho foi desenvolvido nos domicílios da cidade de Pau dos Ferros/RN, trata-se de um estudo realizado em todos os bairros, com o auxílio de dados fornecidos pela CAERN e análise conjunta com o mapa municipal.

Inicialmente realizou-se um levantamento bibliográfico em livros, revistas e dissertações sobre os aspectos gerais dos recursos hídricos (com a finalidade de descrever a água como um bem social público); concessionárias de abastecimento de água (com o objetivo de definir estágio de abastecimento de água por via de concessionárias) e privatizações de abastecimento de água (com o advento de expor a realidade brasileira).

Posteriormente levantou-se o quantitativo de estabelecimento que possuem a tarifa social em Pau dos Ferros/RN. Para obtenção dos dados do levantamento, foram realizadas visitas na CAERN no período de Junho a Agosto de 2017, sendo atendido pelo coordenador comercial da Regional do Alto Oeste.

Por fim, para o acompanhamento dos dados utilizou-se o programa GSAN (Sistemas de Gestão de Serviços de Saneamento), onde as informações são cadastradas e transferidas para relatórios com quantitativos. Com isso, de posse de todos os recursos possíveis elaborouse um mapa de indicador de localidade com índice de cadastro em tarifa social na mancha urbana de Pau dos Ferros-RN. 


\section{RESULTADOS E DISCUSSÃO}

ÁGUA E OS BENEFÍCIOS DAS CONCESSIONÁRIAS PÚBLICAS: O EXEMPLO DO ESTADO DO RIO GRANDE DO NORTE

A Companhia de Águas e Esgotos do Estado do Rio Grande do Norte (CAERN) foi criada no ano de 1969 com a missão de atender toda a população potiguar com água potável, coleta e tratamento de esgotos. Tem como objetivo contribuir para a melhoria da qualidade de vida dos seus usuários, respeitando os fatores sociais econômicos e ambientais. A CAERN possui 165 sistemas de abastecimento de água distribuídos em 153 sedes de municípios e 13 outros pontos de localidades. Possui também 40 sistemas de esgotos em 39 municípios e 1 outro ponto de localidade. Apenas 15 cidades do estado não possuem sistemas de abastecimento de águas fornecido pela companhia.

$\mathrm{O}$ acesso à água está a cada dia mais difícil, tanto por questões ambientais de diminuição de cursos d'água potáveis, quanto pela entrada da água na racionalidade do capital. No Brasil especificamente, passa-se na atualidade por um momento delicado em algumas regiões diante do seu fornecimento hídrico e a possível privatização das companhias de abastecimento vem à reboque pautadas em discursos de melhor gerência e racionalização do abastecimento, o que entende-se ser um risco no que se refere ao acesso a água enquanto direito humano, principalmente para as pessoas de menor poder aquisitivo. Logo, o serviço fornecido por sistemas públicos possui benefícios e valores humanitários que de modo algum devem ser desconsiderados.

Para compreender os valores e benefícios de uma concessionária pública de abastecimento de água, devemos ver os contrapontos por parte das companhias privadas. Silva; Britto (2002) trazem considerações a respeito do capitalismo no fornecimento de água, que deixa de lado os direitos sociais para focar no aspecto econômico, prejudicando inicialmente a população mais pobre, que reside em bairros periféricos e assentamentos, onde passa a existir um aumento na exclusão territorial em investimentos nessas áreas por parte das companhias privadas, já que nesses espaços não se tem respostas economicamente positivas.

Nesse raciocínio, as empresas públicas de abastecimento implementam políticas a fim de diminuir a exclusão e garantir o que é direito de todos. Buscam com maior comprometimento criar estratégias para oferecer serviços de modo mais igualitário. Porém, considerando que não vivemos em um país justo e que o combate à desigualdade caminha em curtos passos, o serviço público com essas estratégias vem a ser primordial no sentido de voltar para o Estado a possibilidade de desenvolvimento para com o seu território. Assim, distanciando-se da abusividade na cobrança pelo serviço prestado, que vem a ser outro ponto 
positivo do sistema público, a implementação da tarifa visa custear despesas de coleta, tratamento e distribuição, tal como para investimentos e melhorias no serviço, o que as tornam bastante distintas, variando de acordo com cada estado considerando sua disponibilidade e facilidade de acesso para coleta. Podemos analisar alguns dados em modo comparativo no gráfico a seguir, com algumas companhias privadas que fornecem seus serviços para cidades nos estados de Tocantins, Rio de Janeiro e Rio Grande do Sul, e companhias públicas de diversos estados no Nordeste e Sudeste do País.

Gráfico 01: Amostra de Tabelas Tarifárias 2017

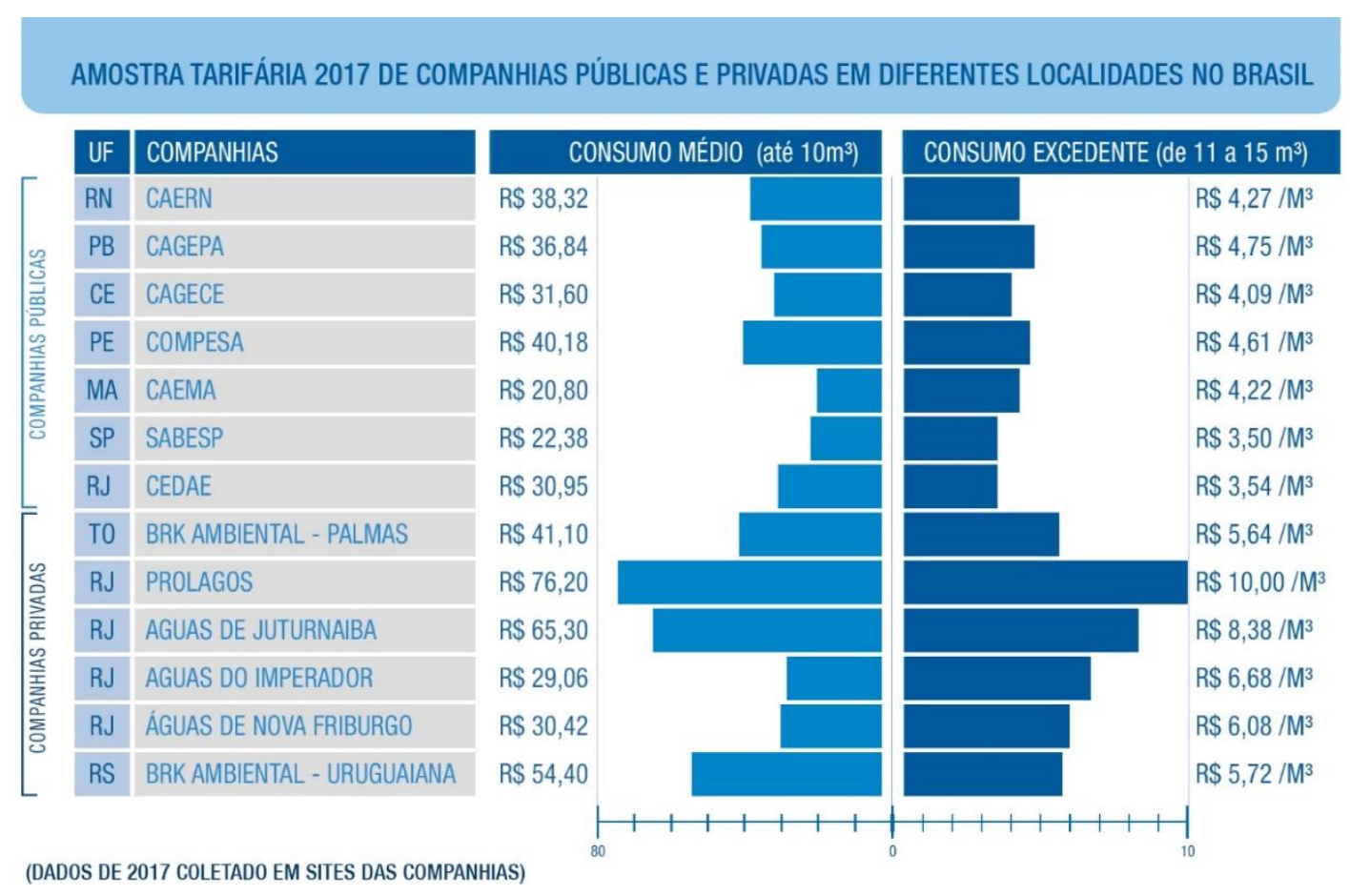

Fonte: Elaborado por Silva Júnior, com coleta de dados em sites das referidas empresas (2017)

Em análise ao gráfico, as concessionárias públicas pesquisadas apresentam uma média tarifária a aproximadamente $\mathrm{R} \$ 31,58$ por uma quantidade de até 10 metros cúbicos $\left(\mathrm{m}^{3}\right)$ de água em seu consumo regular, considerando que suas localidades são no Nordeste do País, onde o difícil acesso a água a tornaria mais cara equiparando com localidades que possuem água em abundância. No entanto as concessionárias privadas mesmo em locais com água mais frequente se comparado a região Nordeste, possuem tarifas mais elevadas, em alguns casos com acréscimo de mais de $100 \%$. Isso reflete o posicionamento de autores já citados anteriormente que relatam as privatizações com elevados valores tarifários e sua influência na exclusão social retirando a água de quem não tem condições de pagar tais valores. 
A avaliação do consumo excedente é de grande importância pois existe a inclusão de um incentivo para sua conservação através dessas tarifas, tornando mais caro progressivamente o uso excessivo da água. Portanto, as companhias públicas adotam um aumento moderado diferente das privadas que salteiam o valor de modo exorbitante.

Introduzindo a CAERN no contexto, a referida concessionária pública detém a concessão do abastecimento de águas do Estado. Sociedade de economia mista, com mais de 95\% de suas ações pertencente ao governo do estado, desde sua criação em 1969 vem atuando em mais de 160 municípios e localidades, desempenhando um papel importante para as famílias que dela dependem diante de cíclicas crises hídricas que permeiam principalmente todo o Nordeste $\mathrm{Seco}^{4}$.

Com valores significativos, veremos no quadro a seguir a tabela tarifária da CAERN do ano de 2017, com informações importantes a cerca de uma das mais baixas tarifas para famílias consideradas de baixa renda.

Quadro 2: Tabela Tarifária 2017 - CAERN

\begin{tabular}{|c|c|c|c|c|c|c|c|c|}
\hline \multirow{2}{*}{ CLASSE DE CONSUMO } & \multirow{2}{*}{$\begin{array}{c}\text { COTA } \\
\text { BÁSICA (m3) }\end{array}$} & \multirow{2}{*}{$\begin{array}{c}\text { VALOR DA } \\
\text { TARIFA MÍNIMA }\end{array}$} & \multicolumn{6}{|c|}{ CONSUMOS EXCEDENTES PARA OS MEDIDOS $\left(\mathrm{m}^{3}\right)$} \\
\hline & & & $11-15 \mathrm{~m}^{3}$ & $16-20 \mathrm{~m}^{3}$ & $21-30 \mathrm{~m}^{3}$ & $31-50 \mathrm{~m}^{3}$ & $51-100 \mathrm{~m}^{3}$ & $>100 \mathrm{~m}^{3}$ \\
\hline & Medido/Ñ Medido & Medido/Ñ Medido & $\mathrm{R} \$ \mathrm{~m} 3$ & $\mathrm{RS} / \mathrm{m} 3$ & $\mathrm{R} \$ \mathrm{~m} 3$ & $\mathrm{R} \$ / \mathrm{m} 3$ & $\mathrm{R} \$ \mathrm{~m} 3$ & $\mathrm{R} \$ \mathrm{~m} / \mathrm{m} 3$ \\
\hline - RESIDENCIAL SOCIAL & 10,00 & 7,73 & 4,27 & 5,05 & 5,69 & 6,55 & 8,48 & 9,64 \\
\hline - RESIDENCIAL POPULAR & 10,00 & 24,34 & 4,27 & 5,05 & 5,69 & 6,55 & 8,48 & 9,64 \\
\hline - RESIDENCIAL & 10,00 & 38,32 & 4,27 & 5,05 & 5,69 & 6,55 & 8,48 & 9,64 \\
\hline - COMERCIAL & 10,00 & 58,96 & 7,44 & 7,98 & 9,64 & 9,64 & 9,64 & 9,64 \\
\hline • INDUSTRIAL & 20,00 & 128,58 & - & - & 10,60 & 10,60 & 10,60 & 10,60 \\
\hline - PÚBLICA & 20,00 & 123,22 & - & - & 10,60 & 10,60 & 10,60 & 10,60 \\
\hline
\end{tabular}

Fonte: Companhia de Águas e Esgotos do Rio Grande do Norte - CAERN, 2017.

Fazendo uma vista ao quadro acima, que demonstra detalhes do valor de consumo excedente por metros cúbicos $\left(\mathrm{m}^{3}\right)$, também apresenta um conjunto de classes onde diversificam os tipos de imóveis cadastrados para adequar cotas e valores distintos de acordo com cada um. Com isso tem-se um ponto bastante importante no que diz respeito às classes sociais destinadas as famílias de baixa renda, que representam pessoas que, por muitas vezes, não tem condições de pagar uma conta em seu valor considerado alto e correm o risco de ter o fornecimento suprimido. Então são definidos requisitos (citados a seguir) que junto ao órgão trará uma possível redução do valor tarifário e, quando adicionado o imóvel em classes de

\footnotetext{
${ }^{4}$ Nordeste Seco é a denominação dada por Ab’Saber (1999) para também abordar o sertão Semiárido brasileiro.
} 
consumo adotadas para concessão de subsídios, estas podem ser divididas em: "residencial social" ou "residencial popular".

Seguindo o padrão médio das concessionárias públicas do Brasil, reduz-se o valor tarifado em até $80 \%$ para essas classes, como é o caso da CAERN. Que por sua iniciativa tornou-se pioneira no Brasil ao incluir em sua Resolução nº 23/2003-CA, que posteriormente modificou na 11/2010-CA, a classificação de 5 requisitos de natureza socioeconômica, no qual o imóvel e usuário precisam se enquadrar em no mínimo 3 para atingir a classe residencial social, e para a residencial popular ao menos 2 (tendo em vista que o primeiro requisito é considerado obrigatório).

Quadro 3: Requisitos para cadastro de Tarifa Social

\begin{tabular}{|c|l|l|}
\hline $\mathbf{N}^{\mathbf{0}}$ & \multicolumn{1}{|c|}{ Requisitos } & \multicolumn{1}{c|}{ Descrição } \\
\hline $\mathbf{1}$ & Cadastro Social & $\begin{array}{l}\text { Estar inscrito em um dos programas sociais do } \\
\text { Governo }\end{array}$ \\
\hline $\mathbf{2}$ & Características do imóvel & Possuir tamanho inferior a 50m² de área coberta \\
\hline $\mathbf{3}$ & Localização & $\begin{array}{l}\text { Estar situada em bairro periférico, favela ou } \\
\text { assentamento }\end{array}$ \\
\hline $\mathbf{4}$ & Caixa d'água elevada & Não possuir reservatório de água elevado \\
\hline $\mathbf{5}$ & Pontos de água & Possuir apenas um ponto (torneira) de coleta de água \\
\hline \multicolumn{2}{|c|}{ Fonte: Companhia de Águas e Esgotos do Rio Grande do Norte - CAERN - Resolução 11/2010-CA } \\
\hline
\end{tabular}

Com essa redução bastante significativa no valor tarifário, as pessoas contempladas serão aquelas que de forma alguma poderiam pagar pelo serviço oferecido se fosse calcular e incluir os custos de tratamento e fornecimento até chegar a porta das casas. Considerando essa redução inviável para obtenção de retorno financeiro, a companhia pública desempenha práticas em prol da diminuição das desigualdades, expandindo seu serviço até os mais baixos pontos periféricos.

\section{MAPEAMENTO DE TARIFA SOCIAL NA CIDADE DE PAU DOS FERROS/RN}

O sistema de abastecimento de água na cidade de Pau dos Ferros -RN ocorre através da CAERN. É um fornecimento bastante irregular, pois seu funcionamento inicial parte da captação a 70 km de distância na Barragem de Santa Cruz localizada na cidade de Apodi/RN, e após o tratamento inicia sua distribuição pela adutora denominada de "engate rápido" com diâmetro de 300mm transportando essa água para atender as necessidades de mais de 11 mil famílias que residem nessa região.

No Rio Grande do Norte, especificamente em Pau dos Ferros, está localizada a Regional Alto Oeste da CAERN, parte da companhia representada nesse território e que 
fornece apoio aos escritórios dos demais municípios. Tendo grande importância para muitas famílias, a companhia responsável pelo abastecimento hídrico enfrenta atualmente junto a população local uma das maiores secas da história, na qual é reconhecido que o atual fornecimento irregular não advém do serviço prestado, mas sim da relevante escassez de água causada pela estiagem. De acordo com os dados apresentados pela empresa, no RN cerca de 35 mil famílias são beneficiadas com a redução tarifária. Na cidade de Pau dos Ferros destacam-se algumas áreas com demandas de famílias cadastradas em programas sociais e, por isso, também contempladas pela companhia com a inclusão no programa.

Atualmente a cidade possui 11.777 imóveis cadastrados nos registros da CAERN, logo 9.119 estão ativos e aptos a receber o fornecimento de água. Cerca de $10 \%$ dessa totalidade são beneficiados no programa da tarifa social. Então, considerando a desatualização cadastral e o crescente conhecimento da população para com o direito do benefício, estimasse que esse valor represente 5\% a mais. Com isso o mapa da cidade adaptado (Figura 03) transparece quais locais possuem um maior índice de beneficiados, assim como também mostra que a concentração maior está nas partes periféricas da cidade. 
Figura 03: Indicador de localidade com índice de cadastro em tarifa social na mancha urbana de Pau dos Ferros-RN

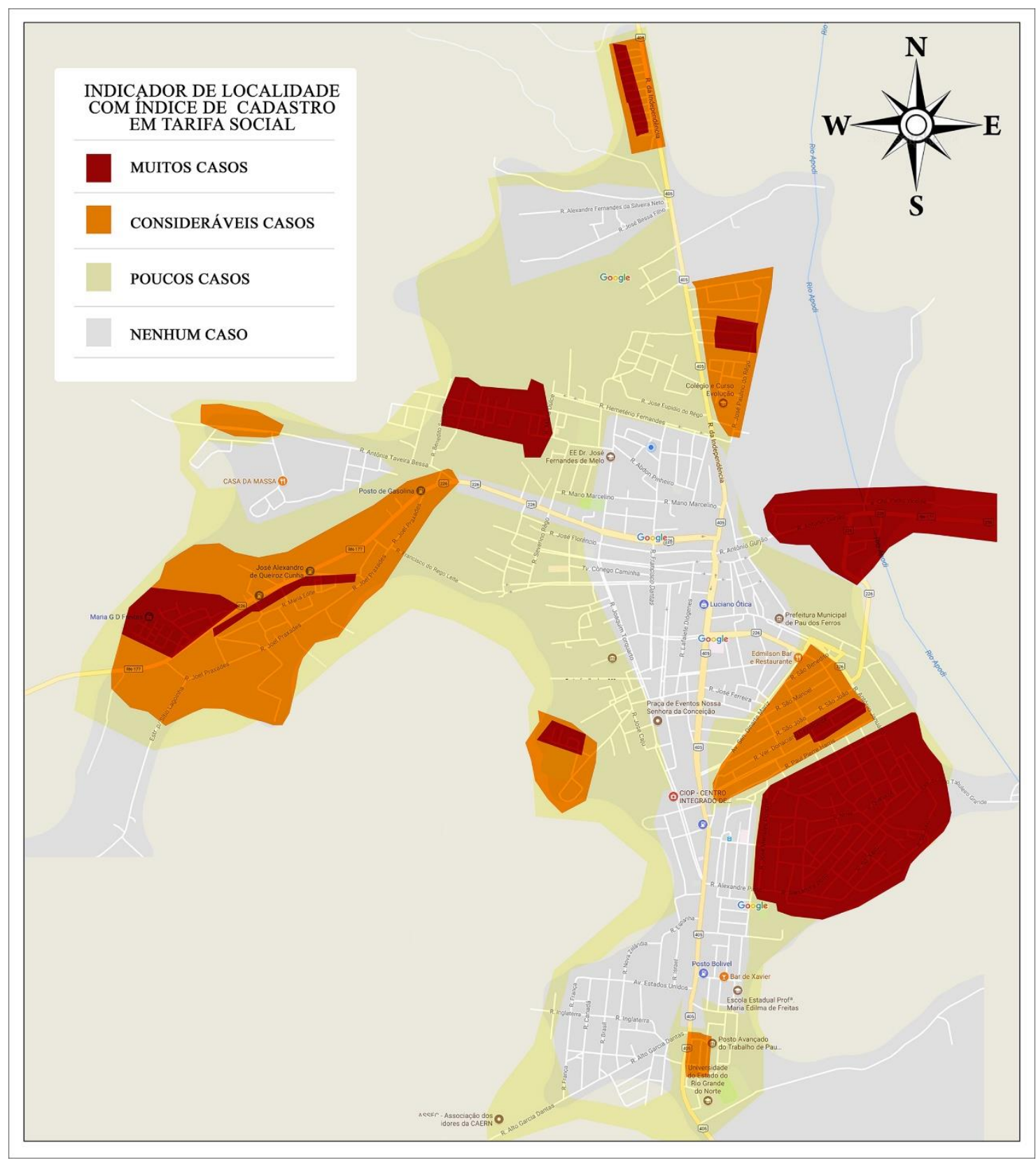

Fonte: Mapa base da CAERN, 2017. Adaptado pelos autores, 2017.

A cidade que é dividida pela companhia por setores em seu sistema integrado, possui áreas periféricas que estão em constante transformação. De acordo com a CAERN, nos últimos 3 anos foram registrados ao menos 300 pedidos de ligações novas na empresa, refletindo a expansão urbana ocasionada por loteamentos e programas habitacionais, aumentando a expectativa de consumo, assim como de famílias em busca do benefício das tarifas reduzidas. 
Entre todos aqueles que possuem o benefício da redução no valor da conta com a tarifa social, o mapa apresenta na cor vermelha as partes periféricas onde se destacam os bairros: Manoel Deodato (com o maior índice de famílias beneficiadas); Alto São Geraldo; Olívio de Souza; Paraíso e Manoel Domingos, com muitos casos de famílias com o benefício.

Posteriormente destacam-se de cor laranja os bairros: Riacho do Meio; São Benedito; São Vicente de Paula e João XXIII, com um regular índice de famílias beneficiadas e, por fim, na cor amarela os bairros: Alto do açude; São Judas Tadeu; Frei Damião; Domingos Gameleira; Bela Vista; Arizona e Chico Cajá, com poucos casos registrados de famílias cadastradas no benefício.

Com isso vemos que a parte central da cidade onde funciona o comércio assim como famílias de melhores rendimentos financeiros residem não possuem famílias beneficiadas. $\mathrm{O}$ bairro Manoel Deodato é o de famílias com menor poder aquisitivo e possui aproximados 1000 imóveis, é nele onde encontra-se situações de vulnerabilidade social e de extrema pobreza, tanto por parte dos imóveis em condições precárias, como as próprias famílias desestruturadas pelos mais diversos motivos que a vulnerabilidade social pode causar.

Com esse reflexo, a CAERN intervém com o compromisso de diminuir os laços da desigualdade, promover atualizações cadastrais a fim de regularizar e incorporar o benefício da tarifa social para todas as famílias que possuem o direito e garantir com um baixo custo o acesso a água potável.

\section{CONSIDERAÇÕES FINAIS}

O desenvolvimento do presente estudo, possibilitou inicialmente uma análise do tema água como um bem de direito público, a partir do reconhecimento como um elemento de uso comum garantido por lei, defendido por autores renomados e organizações como a ONU, tal como o seu reconhecimento internacional. Posteriormente com base nas referências, foram vistos argumentos sobre influências e características das concessionárias privadas sobre as públicas, onde movimentou questionamentos no mundo acerca de possíveis consequências nos processos de privatização do serviço de abastecimento de água, onde, na América Latina obtivemos diversos casos de companhias privadas que devolveram seus serviços para a administração pública por meio de decretos ou por insuficiência administrativa.

Tendo em vista a sua influência na desigualdade e exclusão social, as vantagens apresentadas pelas companhias públicas são de relevante importância como os valores menores cobrados pelo serviço prestado, tal como foi apresentado na coleta de dados que 
claramente demonstra consideráveis variações tarifárias das concessionárias privadas sobre as públicas e essa diferença pode ter forte influência na garantia de água para famílias com menor condição financeira. Logo, como um tema de tamanha relevância, puxado pela onda de privatizações de concessionárias de abastecimento de água no Brasil e no mundo, espera-se com esse artigo ampliar-se a consciência da responsabilização do Estado enquanto provedor dos serviços de abastecimento de água e chamar a sociedade ao debate do direito à água.

\section{REFERÊNCIAS}

AB'SÁBER, Aziz Nacib. Sertões e sertanejos: uma geografia humana sofrida. Estudos Avançados. $13 \quad$ (36), $1999 . \quad$ Disponível <http://www.scielo.br/scielo.php?script=sci_arttext\&pid=S0103-40141999000200002> Acessado em 04 de julho de 2017.

ARMANDO, Nicanor Henrique; VALADÃO, Maristela Aparecida Oliveira. A Dominialidade Privada dos Recursos Hidrícos em face do Desenvolvimento Sustentável. Revista do Direito Público, Londrina, v.8, n.2, p. 35/62, maio/ago. 2013, p. 39/40. Acesso em 10 de julho de 2017.

BRASIL. Constituição da República Federativa do Brasil - 1988. Acesso em: 05 de julho de 2017.

BRASIL, Lei $\mathrm{n}^{\circ} 11.445,2007$ - Lei do Saneamento Básico. Disponível em: 〈http://www.planalto.gov.br/ccivil_03/_ato2007-2010/2007/lei/111445.htm>Acesso em $10 \mathrm{de}$ julho de 2017.

CAVALCANTI, Erivaldo. Água e cidadania: a privatização dos recursos hídricos e os atores sociais. Revista Jurídica (FIC), v. 3, p. 84-102, 2014. Acesso em: 09 de julho de 2017.

RIO DE JANEIRO. Decreto n ${ }^{\circ}$ 24.643, de 10 de julho de 1934. Decreta o Código das Águas. Diário Oficial da União - Sessão 1 - 20/07/1934, Página 14738. Rio de Janeiro, 10 de julho de 1934. Disponível em: <http://www.planalto.gov.br/ccivil_03/decreto/d24643.htm> Acesso em: 05 de julho de 2017.

FLORES, R. K.. O Discurso Como Estratégia de Luta Contra a Mercantilização da Água. Sociedade, Contabilidade e Gestão (UFRJ), v. 4, p. 55-71, 2009. Acesso em: 14 julho de 2017 GRANZIERA, Maria Luiza Machado. Direito de Águas: disciplina jurídica das águas doces. $2^{\mathrm{a}}$ ed. São Paulo: Atlas, 2003.

HELLER, Leo. ONU - Organização das Nações Unidas, Disponível em: $<$ https://nacoesunidas.org/privatizacao-do-saneamento-ja-se-mostrou-inadequada-em-muitospaises-diz-relator-da-onu/> Acesso em: 10 de jul. 2017.

J. G. Tundisi, Água no século XXI: Enfrentando a escassez (Editora RiMa, IIE. 248p, 2003). Acesso em: 10 de outubro de 2017.

JORNAL O GLOBO - BNDES começa a contratar estudos para privatizar saneamento. Disponível em: <https://oglobo.globo.com/economia/infraestrutura/bndes-comeca-contratarestudos-para-privatizar-saneamento-21074500\#ixzz4mMZeNpSP> Acesso em: 10 de julho de 2017.

BRASIL. Lei 9.433 de 08 de janeiro de 1997. Institui a Política Nacional de Recursos Hídricos, cria o Sistema Nacional de Gerenciamento de Recursos Hídricos. Diário Oficial da República Federativa do Brasil, Brasília 10/01/1997, P.470. Disponível em: <http://www.planalto.gov.br/ccivil_03/leis/L9433.htm> Acesso em: 05 de julho de 2017. 
MOREIRA; PEREIRA, Privatização das águas: uma análise na perspectiva latino-americana a partir dos direitos humanos fundamentais FIDES, Natal, v. 8, n. 2, jul./dez. 2016. Acesso em: 09 de julho de 2017.

OLIVEIRA; DE LIMA: Ambiente e Sociedade, São Paulo v. XVIII, n.3 p.253-272. Julset.2015 acesso em: 09 de julho de 2017.

Organização das Nações Unidas - ONU, outubro de 2010, disponível em: <http://www.un.org/apps/news/story.asp?NewsID=36308\#.WV2do4jyvcc> Acesso em: 05 de julho de 2017.

POMPEU, Cid Tomanik. Direito de águas no Brasil. 2. ed., São Paulo: Revista dos Tribunais, 2010. Acesso em 05 de julho de 2017.

SADER, Emir. De olho na crise da água. Revista Eco 21: Tricontinental Editora, ano XV, n. 101, março/2005. Disponível em: <http://www.eco21.com.br/textos/textos.asp?ID=1052>. Acesso em: 14 jul. 2017.

TUROLLA, F. A. Política de saneamento básico: avanços recentes e opções futuras de políticas públicas. IPEA - Instituto de Pesquisa Econômica Aplicada, 2002. Acesso em: 09 de jul. 2017.

CEDAE. Companhia Estadual de Aguas e Esgotos do Rio de Janeiro - Site Institucional. Abela tarifária. Disponível em: <http://www.cedae.com.br/> Acesso em: 19 de agosto de 2017.

CAERN. Companhia de Aguas e Esgotos do Rio Grande do Norte - Site Institucional. Disponível em: <http://www.caern.rn.gov.br/Index.asp> Acesso em: 19 de agosto de 2017.

CAGEPA. Companhia de Aguas e Esgotos da Paraíba - Site Institucional. Tabela tarifária. Disponível em: <http://www.cagepa.pb.gov.br/> Acesso em: 19 de agosto de 2017.

CAGECE. Companhia de Aguas e Esgotos do Ceará - Site Institucional. Tabela tarifária. Disponível em: <https://www.cagece.com.br/> Acesso em: 19 de agosto de 2017.

CAEMA. Companhia de Saneamento Ambiental do Maranhão - Site Institucional. Tabela tarifária. Disponível em: <http://www.caema.ma.gov.br/portalcaema/> Acesso em: 19 de agosto de 2017.

SABESP. Companhia de Saneamento Básico do Estado de São Paulo - Site Institucional. Tabela tarifária. Disponível em: <http://site.sabesp.com.br/site/Default.aspx> Acesso em: 19 de agosto de 2017.

COMPESA Companhia Pernambucana de Saneamento - Site Institucional. Tabela tarifária. Disponível em: < http://servicos.compesa.com.br/> Acesso em: 19 de agosto de 2017.

ODEBRECHT AMBIENTAL / BRK AMBIENTAL. Grupo de Companhias Privadas de Saneamento - Site Institucional. Tabelas tarifárias. Disponível em: <https://www.brkambiental.com.br/> Acesso em: 19 de agosto de 2017.

ÁGUAS DO BRASIL. Grupo de Companhias Privadas de Saneamento - Site Institucional. Tabelas tarifárias. Disponível em: <http://www.grupoaguasdobrasil.com.br/> Acesso em: 19 de agosto de 2017.

Recebido em 13 de dezembro de 2017. Aceito em 23 de março de 2018. 